\title{
Technical Note: Weight approximation of coccoliths using a circular polarizer and interference colour derived retardation estimates - (The CPR Method)
}

\author{
J. Bollmann \\ Department of Earth Sciences, Earth Sciences Centre, University of Toronto, 22 Russell Street, Toronto, \\ Ontario, M5S 3B1, Canada \\ Correspondence to: J. Bollmann (bollmann@es.utoronto.ca)
}

Received: 25 June 2013 - Published in Biogeosciences Discuss.: 8 July 2013

Revised: 7 February 2014 - Accepted: 17 February 2014 - Published: 8 April 2014

\begin{abstract}
A circular polarizer is used for the first time to image coccoliths without the extinction pattern of crossed polarized light at maximum interference colour. The combination of a circular polarizer with retardation measurements based on grey values derived from theoretical calculations allows for the first time accurate calculations of the weight of single coccoliths thinner than $1.37 \mu \mathrm{m}$. The weight estimates of 364 Holocene coccoliths using this new method are in good agreement with published volumetric estimates. A robust calibration method based on the measurement of a calibration target of known retardation enables the comparison of data between different imaging systems. Therefore, the new method overcomes the shortcomings of the error prone empirical calibration procedure of a previously reported method based on birefringence of calcite. Furthermore, it greatly simplifies the identification of coccolithophore species on the light microscope as well as the calculation of the area and thus weight of a coccolith.
\end{abstract}

\section{Introduction}

Coccolithophores play a major role in the global carbon cycle and there is increasing concern that ocean acidification will affect the calcification in this group of phytoplankton (e.g., Doney et al. 2009). In order to quantify future and past effects of ocean $\mathrm{pH}$ on the calcium carbonate production of coccolithophores as a group or on the calcification of individual species, accurate estimates of coccolith mass are required. Methods to quantify the carbonate weight of coc- colithophores range from simple weighing the fine fraction of a sediment sample (Broerse et al., 2000) or weighing the samples before and after dissolving the calcium carbonate fraction (Bairbakhish et al., 1999), to elaborated morphometric measurements to estimate the weight of single coccoliths (Young and Ziveri, 2000; Beaufort and Heussner, 1999). A detailed review of the advantages and biases of these methods is given in Beaufort (2005).

Recently, efficient quantification methods were described based on the optical properties of calcite (birefringence). Guay and Bishop (2002) were first to report a method to quantify the bulk carbonate content of plankton samples using birefringence of particles in suspension with a benchtop spectrophotometer. However, the proposed method only allows for the quantification of bulk carbonate content and not the analysis of single coccoliths. Beaufort (2005) described a method that allows for the quantification of the weight of single coccoliths based on the optical properties of calcite. It was first applied by Engel et al. (2005) and since then several studies have used this method (Beaufort et al., 2008; Grelaud et al., 2009; Beaufort et al., 2011; Cubillos et al., 2012; Beaufort et al., 2007; Bordiga et al., 2012; Horigome et al., 2013; Bauke et al., 2013; Bach et al., 2012). However, the transfer function reported by Beaufort (2005) is based on an error prone calibration method and suffers from a sub-optimal segmentation of coccoliths in crossed polarized light. Here, a new method is proposed that overcomes most of the limitations of the method reported by Beaufort (2005). 


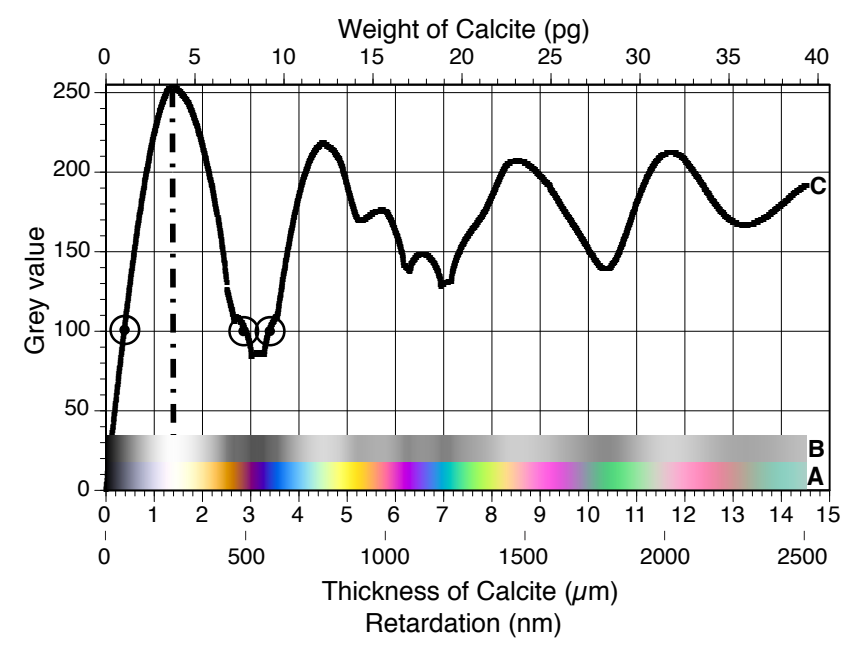

Fig. 1. Relationship between interference colour, retardation, thickness and weight of calcite. (A) Michel-Lévy colour chart calculated in $1 \mathrm{~nm}$ steps retardation after Sørensen (2013); (B) and (C) conversion of the Michel-Lévy colour chart (RGB) into grey values from 0-255 using ImageJ. The thickness and weight of calcite were calculated according to Eqs. (1) and (2), respectively. The dashed dotted line (-'-) indicates the boundary, beyond which, the weight of calcite can not be determined using the relationship between grey values and thickness of a pixel. Marker $(\odot)$ indicates the different thicknesses/weights for a grey value of 100 assuming a pixel area of $0.0225 \mu \mathrm{m}^{2}: 2.9 \mu \mathrm{m}, / 0.177 \mathrm{pg} ; 3.4 \mu \mathrm{m} / 0.207 \mathrm{pg}$ or just $0.38 \mu \mathrm{m} / 0.023 \mathrm{pg}$.

\section{Material and methods}

\subsection{Conventions}

The standard grey value scale is used here where black is 0 and white is 255 ( 8 bit grey scale). Pixel resolution refers to the size of a pixel and not to the optical resolution of the microscope. Please note that the pixel resolution changes with different imaging set-ups such as CCD chip size and optical resolution of the microscope (for details see Sect. 4.2).

\subsection{Theoretical background}

Birefringence of a mineral can be used to calculate the thickness of a particle if the particle is observed in Crossed Polarized Light (XPL) and Circular Polarized Light (CPL). In XPL/CPL the maximum interference colour of a particle systematically changes with the thickness of the particle. The interference colours are the result of the difference between the refraction index of the slow ray (ns) and that of the fast ray (nf) in a birefringent crystal. This difference increases with increasing thickness of the crystal and is called retardation $(r=\mathrm{ns}-\mathrm{nf}$, measured in $\mathrm{nm})$. Zero nm retardation corresponds to black and for first order interference colours a retardation of $0-550 \mathrm{~nm}$ corresponds to black, grey, white, yellow and red (see Fig. 1a). If retardation and birefringence are known, the thickness and thus weight of a particle (e.g., a coccolith) can be calculated as follows (Delly, 2003):

$t=\frac{r}{b \times 1000}$

where $t=$ thickness $(\mu \mathrm{m}), r=$ retardation in $\mathrm{nm}, b=$ birefringence ( 0.172 for calcite)

$w=a \times t \times d$

where $w=$ weight $(\mathrm{pg}) ; a=$ surface area $\left(\mu \mathrm{m}^{2}\right) ; t=$ thickness $(\mu \mathrm{m}) ; d=$ density $\left(\mathrm{g} \mathrm{cm}^{-3} ; 2.71\right.$ for calcite).

In order to obtain the correct thickness of a particle, the highest interference colour/retardation of a particle has to be determined. This is achieved by rotating the particle under XPL until it shows the highest interference colour. The colour is then compared with colours shown on the MichelLévy colour chart. This is a simple standard method for the analysis of minerals. There are, however, several more accurate but also more elaborate ways such as the Brace-Köhler analysis and the Senarmont compensator method to measure the retardation and thickness of birefringent material (Bloss, 1961; Zhang et al., 2013).

The Michel-Lévy interference colour chart, from which there are various versions and editions (Delly, 2003), has been recently revised by Sørensen (2013) and therefore, it has been used in this study instead of the widely used charts of Zeiss or Leica. The new chart provides an improved representation of the interference colours. The calculation of interference colours was done in $1 \mathrm{~nm}$ steps retardation (Sørensen, 2013).

A detailed explanation of the optical properties of minerals and their analysis (beyond the scope of this study) is given in Raith et al. (2012).

\subsection{Imaging}

All images were taken with a Zeiss Axio Imager Z1 equipped with a circular polarizer (Benford plate, Craig, 1961), a PlanApo $100 \times, 1.4$ NA oil objective, 0.9 NA universal condenser, $1.6 \times$ optovar, and a Canon 60D DSLR camera. A detailed explanation about the application and the required optics for a circular polarizer are given in Frohlich (1986), Higgins (2010) and Craig (1961). The camera resolution was set to $1920 \times 1280$ resulting in a pixel resolution of $0.002 \mu \mathrm{m}^{2}$. A micrometer scale with $10 \mu \mathrm{m}$ divisions was used for size calibration (S8 Stage micrometer (02A00404) from PYSER-SGI LTD; overall accuracy $<0.0015 \mathrm{~mm})$

\subsection{Illumination and retardation calibration}

The illumination of the microscope was set to a constant colour temperature of $3200 \mathrm{~K}$ (for details on how to control the colour temperature on a microscope see: http://micro.magnet.fsu.edu/primer/photomicrography/ colortemperature.html). The field aperture diaphragm of the 
microscope, neutral density filter, and shutter time as well as the film sensitivity of the camera and white balance were adjusted to match the interference colour/grey value of a quarter wave platelet $(140 \mathrm{~nm} \pm 3 \mathrm{~nm}$ retardation; grey value $=194$; see Supplement 1).

\subsection{Image analysis}

For image analysis (particle segmentation/detection) and volume calculation, the programmes ImageJ (http://rsb.info.nih. gov/ij/) and AnalySIS 5 PRO, Olympus were used. Volume and weight calculations were done as follows: images in CANON RAW image format were converted into Adobe DNG format and exported from Photoshop into JPEG format with a GAMMA of 0.5. Subsequently, JPEG images were converted into 8 bit greyscale images and the threshold for image segmentation and particle detection was set (background $\sim 10$ grey values). The [calibration] function of ImageJ was used to link grey values to weight per grey value $($ grey value $=$ thickness $\times 2.71$ (calcite density)) and a 4th degree polynomial function was used to fit the data calculated from the interference colours in $1 \mathrm{~nm}$ step retardation (Sørensen, 2013). The weight of a particle was calculated using the [Analyze Particle ...] function of ImageJ where the weight of a particle is shown as [Integrated Density] (for details see http://rsbweb.nih.gov/ij/) and is the sum of all pixel values of one particle/coccolith.

\subsection{Microscope slide preparation}

Sediment suspensions were sprayed onto a glass slide to provide isolated particles that can be easily segmented (Bollmann et al., 1999; McIntyre et al., 1967; Bollmann et al., 2004) and a cover slip was mounted on the slide using Canada balsam. One Holocene sample (GEOB3602, 0-1 cm, Lat. $34^{\circ} 47.4^{\prime} \mathrm{S}$ Long. $17^{\circ} 45.3^{\prime} \mathrm{E}, 1885 \mathrm{~m}$ water depth) and one Late Pleistocene sample (DSDP 119-1-1, $31 \mathrm{~cm}$, Lat. $45^{\circ} 01.90^{\prime} \mathrm{N}$, Long. $7^{\circ} 58.49^{\prime} \mathrm{W}$, water depth: $4447 \mathrm{~m}$ ) were used.

\section{Results}

The conversion of interference colours of the latest colour chart by Sørensen (2013) into grey values shows that grey values increase approximately linearly from black to white (retardation $0-\sim 236 \mathrm{~nm}$; Fig. 1). A retardation of $236 \mathrm{~nm}$ corresponds to a maximum grey value of 253 ( white; Fig. 1b, c) and to a thickness of a calcite crystal of about $1.37 \mu \mathrm{m}$. Particles with a thickness from $1.37 \mu \mathrm{m}(236 \mathrm{~nm})$ to $1.45 \mu \mathrm{m}$ have the same grey value of $253(249 \mathrm{~nm}=$ average thickness of $1.41 \mu \mathrm{m}$ ).

A regression analysis of the relationship between calcite weight calculated using Eq. (2) (thickness up to $1.41 \mu \mathrm{m}$; pixel area $=1 \mu \mathrm{m}^{2}$ ) and grey values obtained from the conversion of interference colours of the latest colour chart by
Sørensen (2013) revealed an $R^{2}$ of 0.99 for a 4th degree polynomial function. Therefore, the weight of calcite associated with a grey value can be estimated using the following formula:

$Y=a+b x+c x^{2}+d x^{3}+e x^{4}$

where $Y=$ weight per grey value $(\mathrm{pg}) ; x=$ grey value; $a=$ $7.14 \mathrm{E}-02 ; b=3.13 \mathrm{E}-03 ; c=1.45 \mathrm{E}-04 ; d=-1.01 \mathrm{E}-6$; $e=2.42 \mathrm{E}-9$.

If the area of a particle and the corresponding number of pixels is known, the total weight of a calcite particle is the sum of all weights/grey values of all pixels belonging to the particle (see Sect. 2.5). In XPL, however, the area of a coccolith is not easily estimated as the optical axis of coccolith crystal units is often oblique to the optical axis of the microscope and arranged in a radial pattern (for details see Young and Bown (1997)). Therefore, parts of a coccolith are black/extinct in XPL (extinction pattern) and can not be separated from the dark background.

To overcome the problem of estimating the coccolith area using polarized light, a Benford plate (Craig, 1961) was inserted between the polarizer and analyser in order to generate circular polarized light (Higgins, 2010;Frohlich, 1986). This simple device eliminates the extinction pattern caused by the crossed polarizing filters and coccoliths exhibit their highest interference colours independent of their orientation with respect to the polarizer and analyser. Thus the CPL method eliminates a major source of error and uncertainty for the weight estimates and it significantly simplifies the identification of coccolithophore species (Fig. 2a-p). The weight difference using the outline/area between XPL and CPL is about $45 \%$. For example, XPL gives a weight of 10 pg (Fig. 2q) and CPL a weight of $18 \mathrm{pg}$ (Fig. 2r) for the Gephyrocapsa oceanica specimen shown in Fig. 2c.

About 360 single coccoliths of 16 Holocene coccolithophore taxa were analysed using the new weight transfer function in combination with the new imaging technique (Table 1; Supplement 2). Weight estimates are well within the range of published values for coccoliths of the family Noelaerhabdaceae and coccoliths of Incertae Sedis taxa Umbellosphaeraceae and Florisphaera (Fig. 2a-f, Fig. 3a-f). Furthermore, the weight of coccoliths of Rhabdosphaera sp. can be estimated up to a length of about $9.5 \mu \mathrm{m}$. Larger specimens exhibit yellow interference colours and are therefore outside of the calibration range (Figs. $2 \mathrm{~g}, 3 \mathrm{~g}$ ). In contrast, the weight of coccoliths of the order Zygodiscales, Coccolithales and the family Syracosphaeraceae (Fig. 2i-p; Fig. 3ip) can not be simply calculated using birefringence because the $\mathrm{C}$-axis orientation of some crystal units has been reported to be parallel to the optical axis of the microscope and thus appear to be dark both in XPL and CPL (V-units according to Young and Bown (1997)). For example, the distal shield of Coccolithus pelagicus, Calcidiscus leptoporus and Umbilicosphaera spp. consist of vertically arranged crystal units 


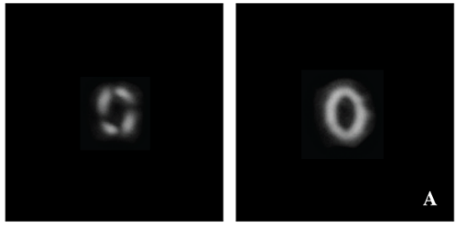

E. huxleyi/small placoliths

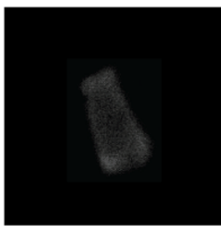

F. profunda

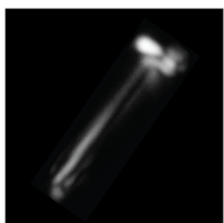

Rhabdosphaera sp.

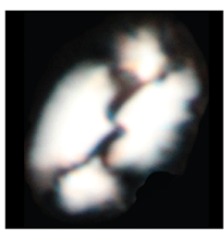

Helicosphaera sp.

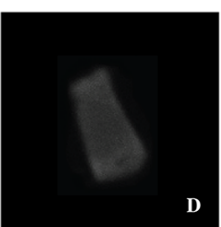

D

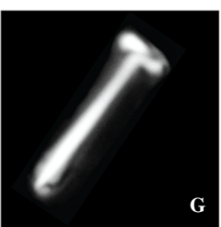

G

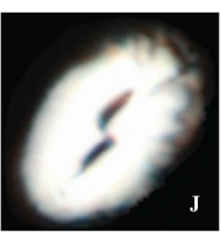

$\mathbf{J}$

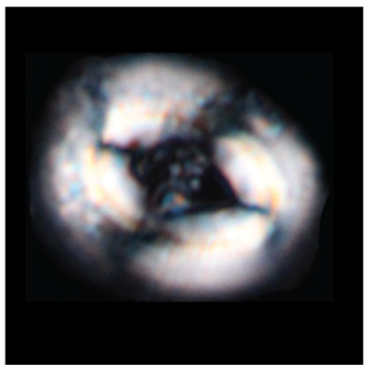

C. pelagicus

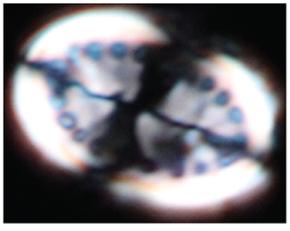

P. discopora

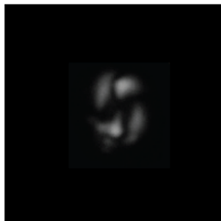

G. muellerae

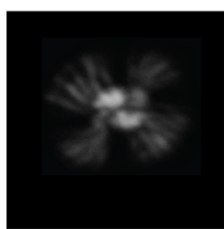

\section{U. tenuis}

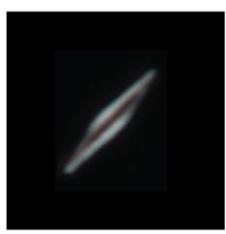

Calciosolenia sp.

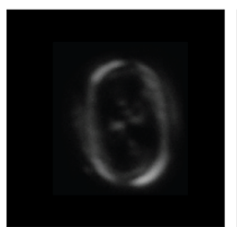

Syracosphaera $\mathrm{sp}$.

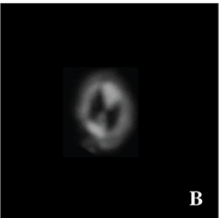

B

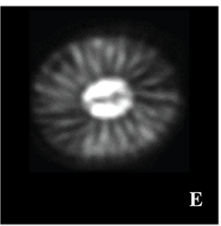

E

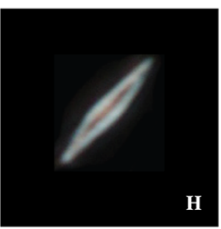

H

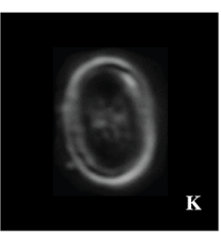

$\mathbf{K}$

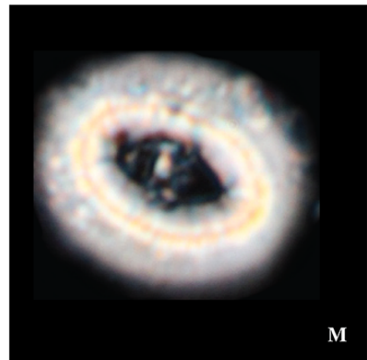

M

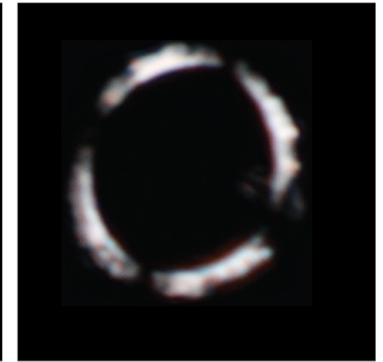

Ceratolithus HET

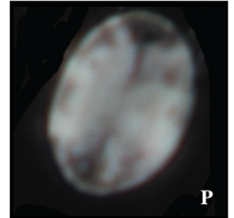

$P$.japonica

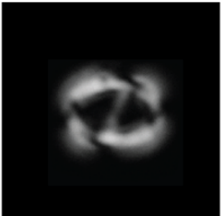

G. oceanica

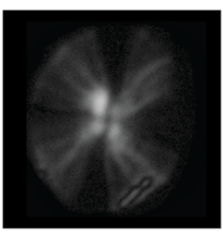

U. irregularis

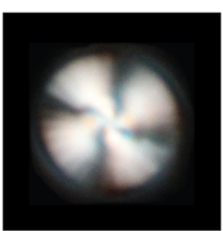

C. leptoporus
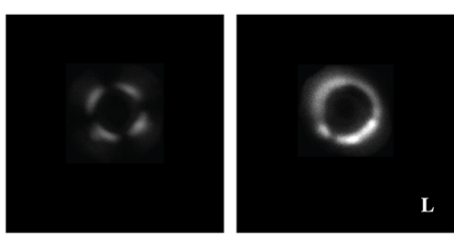

Umbilicosphaera sp.

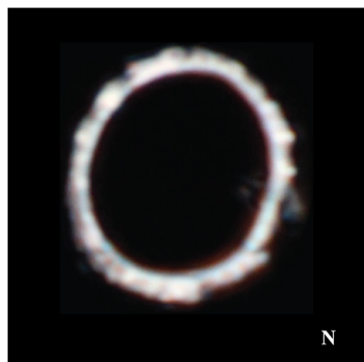

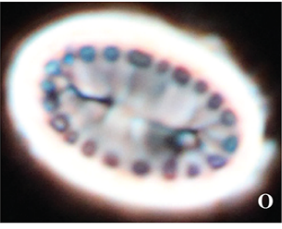
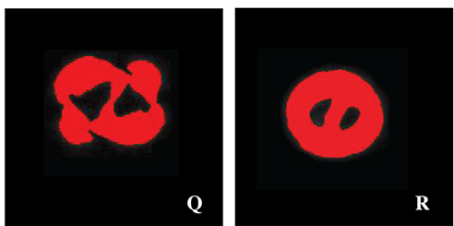

Particle detection in XPL left and CPL right. See specimen figure $2 \mathrm{C}$.

$10 \mu \mathrm{m}$

Fig. 2. Holocene coccoliths depicted in XPL and CPL. (A-O) show the same specimens in XPL (left image) and in CPL (right image). All images were taken on a ZEISS Axio Imager Z1 equipped with a PlanApo. 1.4 NA, 100x oil objective, 0.9 NA universal condenser and a Canon 60D. (Q) and (R) Difference in coccolith segmentation/detection and resulting difference in weight estimates using (Q) XPL: 10 pg and (R) CPL: $18 \mathrm{pg}$, respectively. Scale bar $=10 \mu \mathrm{m}$. 

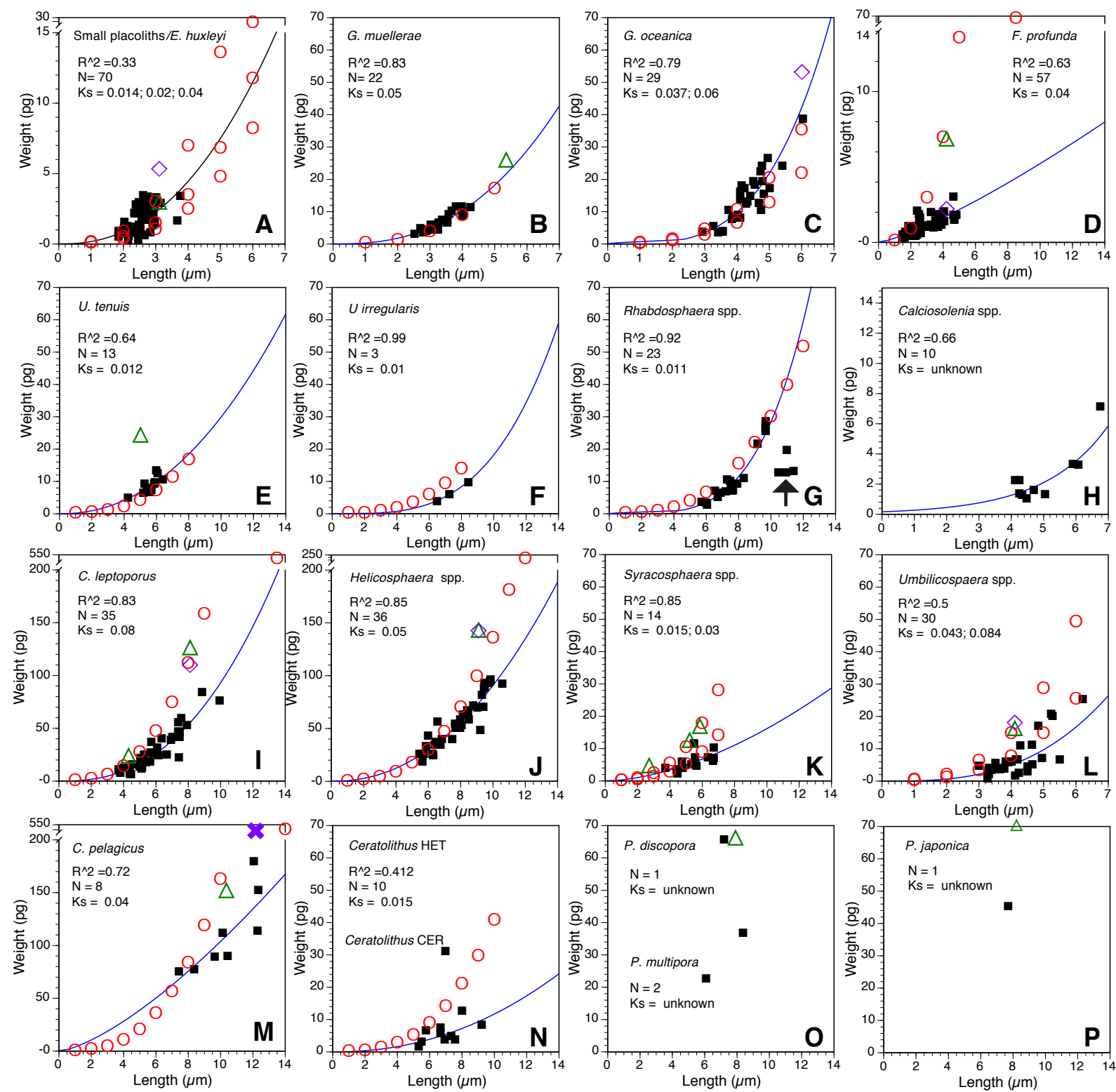

- This study $\bigcirc$ Young \& Ziveri (2000) $\Delta$ Beaufort \& Heussner (1999) $\diamond$ Beaufort (2005) $\quad$ ^ Cubillos et al. (2012)

Fig. 3. Comparison between weight estimates of 16 Holocene coccolith taxa obtained with the new method and published values. $K_{\mathrm{S}}=$ shape factor introduced by Young and Ziveri (2000); the weight of a coccolith was calculated as follows: Weight $=K_{\mathrm{S}} \times(\text { Length })^{3} \times 2.71($ density of calcite). Minimum and maximum $K_{\mathrm{S}}$ values given by Young and Ziveri (2000) were used to calculate the coccolith weights; values for maximum length of coccoliths for E. huxleyi were reported by Bollmann and Herrle (2007), for Gephyrocapsa spp. by Bollmann (1997) and Bollmann et al. (2010), for F. profunda by Quinn et al. (2005), for C. leptoporus by Knappertsbusch et al. (1997), for C. pelagicus by Parente et al. (2004). Values for all other species were taken from Young and Ziveri (2000). The blue line represents a power curve fit. Number of data points (N; black squares) and the correlation coefficient $\left(R^{2}\right)$ for the power fit is given for each species. The arrow in Fig. $3 \mathrm{~g}$ indicates Rhabdosphaera spp. larger than $9.5 \mu \mathrm{m}$.

that are expected to be dark/extinct in XPL/CPL and indistinguishable from the dark background. Consequently, the new method systematically underestimates the weights of coccoliths of these taxa when compared to weight estimates based on the volumetric method (Young and Ziveri (2000); Beaufort and Heussner (1999)) (Fig. 3i-n). Furthermore, coccol- iths of C. pelagicus, Helicosphaera sp. and C. leptoporus larger than $\sim 8 \mu \mathrm{m}$ show yellow-reddish interference colours indicating that their thickness is beyond the valid measurable thickness of $1.41 \mu \mathrm{m}$ as mentioned above (Fig. 2i, j, m; Fig. 3i, j, m). 
Table 1. Comparison of published weight estimates. $N=$ Number of measurements; STDEV $=$ Standard deviation of weight estimates reported; $K_{\mathrm{S}}=$ shape factor reported by Young and Ziveri (2000). Values for maximum length of single coccoliths for E. huxleyi were reported by Bollmann and Herrle (2007), for Gephyrocapsa spp. by Bollmann (1997) and Bollmann et al. (2010), for F. profunda by Quinn et al. (2005), for C. leptoporus by Knappertsbusch et al. (1997), for C. pelagicus by Parente et al. (2004). Values for all other species were taken from Young and Ziveri (2000). Please note that the average length for populations are significantly smaller, for example, for E. huxleyi the maximum average length of a Holocene sample is smaller than $4 \mu \mathrm{m}$ although the maximum size of a single coccolith can be up to $6 \mu \mathrm{m}$ (Bollmann and Herrle, 2007).

\begin{tabular}{|c|c|c|c|c|c|c|c|c|c|c|c|c|c|c|}
\hline & Taxa & $N$ & 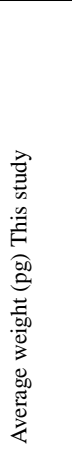 & 㭊 & 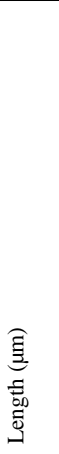 & 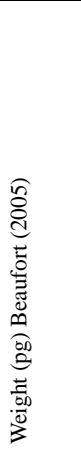 & 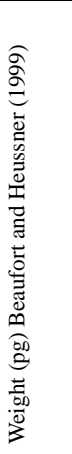 & 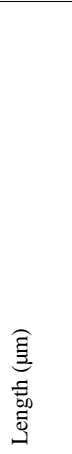 & 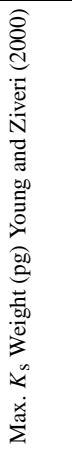 & 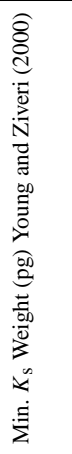 & 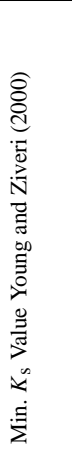 & 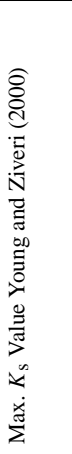 & 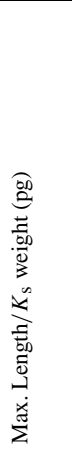 & 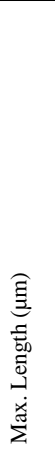 \\
\hline A & Small placoliths/E. huxleyi & 70 & 1.7 & 0.9 & 2.5 & 5.3 & 2.9 & 3.10 & 1.7 & 0.6 & 0.014 & 0.040 & 23.4 & 6.0 \\
\hline B & G. muellerae & 22 & 7.0 & 2.7 & 3.6 & - & 25.7 & 5.35 & 6.3 & 6.3 & 0.050 & 0.050 & 16.9 & 5.0 \\
\hline $\mathrm{C}$ & G. oceanica & 29 & 14.5 & 8.0 & 4.3 & 53 & - & - & 12.9 & 8.0 & 0.037 & 0.060 & 35.1 & 6.0 \\
\hline $\mathrm{D}$ & F. profunda & 57 & 1.0 & 0.6 & 2.6 & 2.2 & 6.8 & 4.20 & 2.9 & 1.4 & 0.030 & 0.060 & 99.9 & 8.5 \\
\hline $\mathrm{E}$ & U. tenuis & 13 & 8.4 & 2.7 & 5.6 & - & 23.9 & 5.00 & 7.6 & 5.7 & 0.012 & 0.016 & 22.2 & 8.0 \\
\hline $\mathrm{F}$ & U. irregularis & 3 & 7.7 & 3.3 & 7.8 & - & - & - & 12.9 & 12.9 & 0.010 & 0.010 & 13.9 & 8.0 \\
\hline $\mathrm{G}$ & Rhabdosphaera spp. & 23 & 11.7 & 7.6 & 8.3 & 46 & - & - & 40.3 & 17.0 & 0.011 & 0.026 & 121.8 & 12.0 \\
\hline $\mathrm{H}$ & Calciosolenia spp. & 10 & 2.5 & 1.8 & 5 & - & - & - & - & - & - & - & - & - \\
\hline I & C. leptoporus & 35 & 30.0 & 19.0 & 6 & 109 & 125.0 & 8.10 & 60.3 & 39.8 & 0.068 & 0.103 & 686.8 & 13.5 \\
\hline $\mathrm{J}$ & H. carteri & 36 & 57.1 & 23.0 & 9.1 & 142 & 143.0 & 9.11 & 102.1 & 102.1 & 0.050 & 0.050 & 234.1 & 12.0 \\
\hline $\mathrm{K}$ & S. pulchra/Syracosphaera spp. & 14 & 5.9 & 2.7 & 5.4 & $10-22$ & 17.0 & 5.85 & 14.1 & 6.4 & 0.015 & 0.033 & 30.7 & 7.0 \\
\hline $\mathrm{L}$ & U. sibogae & 30 & 7.0 & 6.1 & 4.1 & 18 & 16.0 & 4.10 & 15.7 & 8.0 & 0.043 & 0.084 & 49.2 & 6.0 \\
\hline M & C. pelagicus & 8 & 111.3 & 37.2 & 10.3 & - & 151.2 & 10.35 & 207.3 & 118.5 & 0.040 & 0.070 & 520.5 & 14.0 \\
\hline $\mathrm{N}$ & Ceratolithus HET & 10 & 5.8 & & 6.7 & - & - & - & 13.0 & 12.2 & 0.015 & 0.016 & 43.4 & 10.0 \\
\hline $\mathrm{N}$ & Ceratolithus CER & 1 & 31.2 & 3.1 & 6.9 & - & - & - & 89.0 & 86.4 & 0.097 & 0.100 & 360.7 & 11.0 \\
\hline $\mathrm{O}$ & P. discopora & 1 & 65.0 & & 7.2 & - & - & 7.90 & - & - & - & - & - & - \\
\hline $\mathrm{O}$ & P. multipora & 2 & 30.0 & 10.0 & 7.2 & - & - & - & - & - & - & - & - & - \\
\hline $\mathrm{P}$ & $P$. japonica & 1 & 45.0 & & 7.7 & - & 70.1 & 8.20 & - & - & - & - & - & - \\
\hline
\end{tabular}
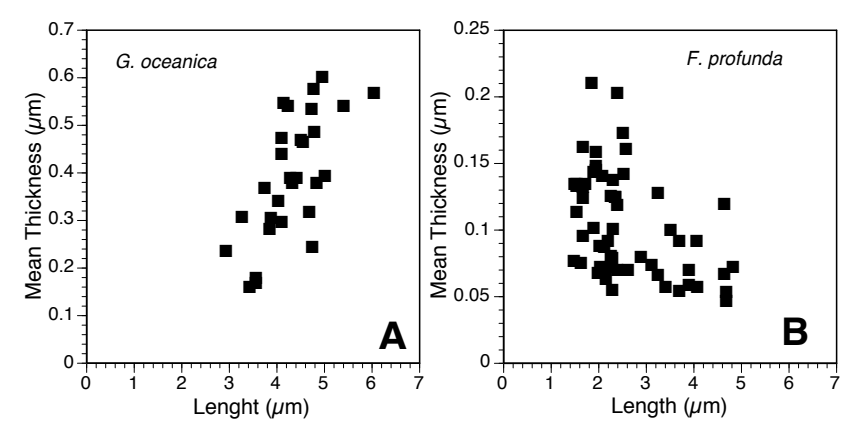

Fig. 4. Scatter plots of length versus thickness for G. oceanica (A) and $F$. profunda $(\mathbf{B})$ indicating that the thickness of $F$. profund $a$ does not increase with increasing length as it does in most other species.

\section{Discussion}

The good agreement between weight estimates based on volumetric/biometric weight estimates (Young and Ziveri, 2000) and the proposed method (Fig. 3a-c, e-f) validates the applicability to weight estimates of coccoliths of the family
Noelaerhabdaceae and coccoliths of Incertae Sedis taxa Umbellosphaeracea. However, the weight estimates for F. profunda differ significantly from published values (Fig. 3d). The weight estimates of $F$. profunda coccoliths do not increase with increasing length as expected (Young and Ziveri, 2000) and as observed for most other species such as $G$. oceanica (Fig. 4). One possible explanation for the difference is that the three different morphotypes/varieties of $F$. profunda (Quinn et al., 2005) have different shape factors $\left(K_{S}\right.$ values) or do not follow the formula:

Volume $=K_{\mathrm{s}} \times(\text { Length })^{3}$

where $K_{S}$ is the species specific shape factor (Young and Ziveri, 2000)

Furthermore, $F$. profunda nannoliths might be constituted of aragonite or vaterite, calcium carbonate minerals with different optical properties than calcite. However, both minerals are metastable conflicting with the wide occurrence of $F$. profunda in deep sea sediments.

Also, the relatively large scatter of weight estimates for E. huxleyi/small placoliths (Fig. 3a) might be explained by 
the presence of different morphotypes and species, as well as varying degrees of preservation. E. huxleyi comprises several morphotypes with different $K_{s}$ values (Young and Ziveri, 2000 ) that can not be separated using a light microscope. Furthermore, most coccoliths smaller than $\sim 3 \mu \mathrm{m}$ can not be unequivocally recognised as E. huxleyi, Gephyrocapsa spp. or Reticulofenestra spp. using a light microscope. All of these taxa have different $K_{s}$ values that might contribute to the scatter in Fig. 3a.

Most weight estimates reported by Beaufort (2005) appear to be higher than the values reported here even when the maximum coccolith length for a given species is assumed (Fig. 3; Table 1). This is surprising as the method is also based on birefringence of calcite. One possible explanation for the discrepancies is the calibration method used by Beaufort as it is not based on the thickness of individual particles as derived from their interference colour (grey value) but relies on the relation between the averaged grey value of all pixels in a field-of-view to the assumed or measured weight of calcite in the same field-of-view. Beaufort (2005) used linear regression analysis to describe the relation between average grey value/px per field-of-view and the average weight per pixel (pg/px) to derive a transfer function for coccolith weight estimates (Fig. 5). This is based on the assumption that the number of particles in a field-of-view and, therefore, its corresponding average grey value, increases linearly with sample weight. However, since according to the re-calculated Michel-Lévy colour chart by Sørensen (2013) the increase of grey values with increasing thickness of calcite does not follow a linear function (Figs. 1, 5d). The use of a linear function systematically overestimates thickness leading to an overestimate of the weight, both in CPL and XPL (Fig. 5d). Another factor that further contributes to overestimation of the weight is that particles do not always show their maximum interference colour/grey value in XPL. A particular problem is particles that are always black/extinct in XPL and CPL if their C-axis orientation is parallel to the optical axis of the microscope. This results in an increase of the average pixel weight per field-of-view but not in an increase of the average grey value per field-of-view. The level of inaccuracy strongly depends on particle orientation that varies with the shape of crystals and hence the type of calcite powder used for calibration and the preparation method (e.g., preferred orientation of elongated particles using flowing water in a filtration device or during smear side preparation). Finally, the use of particles outside the valid range from 0 to $1.41 \mu \mathrm{m}$ would lead to underestimating particle thickness and overestimating particle weight as particles larger than $1.41 \mu \mathrm{m}$ can have the same grey value representation as particles smaller than $1.41 \mu \mathrm{m}$. For example, a pixel with a grey value of 100 can correspond to a thickness/weight of $2.9 \mu \mathrm{m} / 0.176 \mathrm{pg} ; 3.4 \mu \mathrm{m} / 0.206 \mathrm{pg}$ or just $0.38 \mu \mathrm{m} / 0.023 \mathrm{pg}$ (Fig. 1).

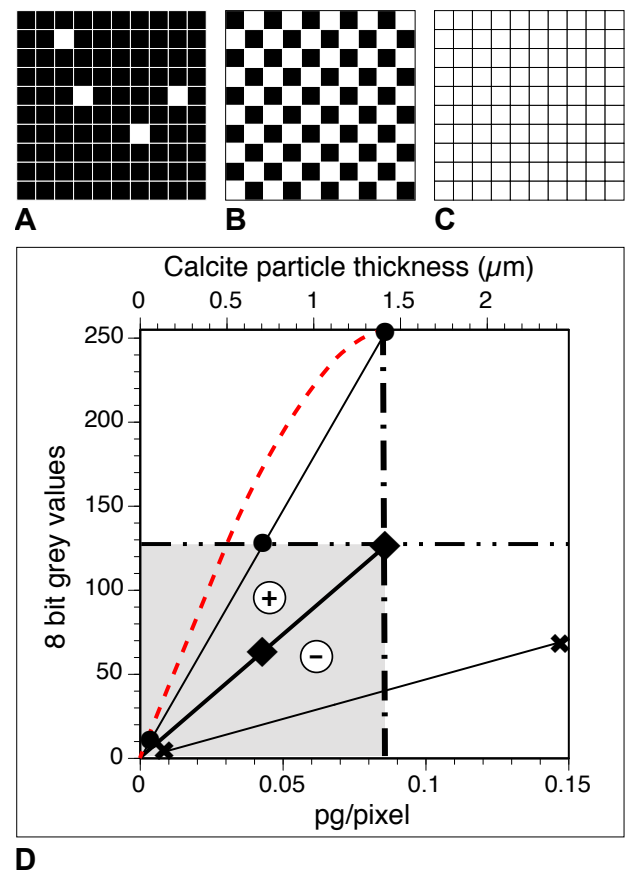

Fig. 5. Principle of the empirical calibration method reported by Beaufort (2005). a-c Camera sensors and field-of-views (FOV) with $10 \times 10$ pixel each $0.0225 \mu^{2}$ in size and varying number of particles each the size of one pixel; (A) FOV with 4 particles resulting in an average grey value of 10; (B) FOV with 50 particles and an average grey value of 126.5; (C) FOV with 100 particles with an average grey value of 253 per pixel; (D) Grey value per pixel as a function of particle thickness in $(\mu \mathrm{m})$ or particle weight (pg/pixel). The red dashed line (...) is the conversion of the Michel-Lévy colour chart (RGB) calculated in $1 \mathrm{~nm}$ steps retardation by (Sørensen, 2013) into grey values from 0-253 (max. thickness of 1.41 $\mu \mathrm{m}$ ). Black dots $(\bullet)$ indicate the average grey value and weight per FOV for the three FOV shown in Fig. 5a-c using CPL assuming a uniform particle thickness of $1.41 \mu \mathrm{m}$ (similar values would be obtained using XPL if particles were all oriented as to present maximum interference colour). Black crosses ( $\mathbf{x})$ indicate the same as above but for a particle thickness of $3.5 \mu \mathrm{m}$ and a corresponding grey value of 100 . Black diamonds $(\diamond)$ indicate the average grey value and weight per pixel for the three FOV shown in Fig. 5a-c using XPL assuming a uniform particle thickness of $1.41 \mu \mathrm{m}$. Here a random orientation of particles is assumed, leading to a different relationship between grey values and weight as compared to the curve using the CPL method (black dots). The maximum average grey value per pixel can not exceed 126.5 (253/2). The dashed single dotted vertical line $\left(-_{-}\right)$indicates the boundary (thickness of $1.41 \mu \mathrm{m}$ and weight of $0.086 \mathrm{pg}$ assuming a pixel size of $0.0225 \mu \mathrm{m}^{2}$ ), beyond which, the weight of calcite can not be determined using the relationship between grey values and thickness of a pixel. The dashed double dotted horizontal line (...) indicates the boundary, beyond which, the grey value can not be used to determine the weight of a pixel in XPL. All calibration points using the empirical calibration method of Beaufort (2005) should lie within the area defined by the grey value and weight boundaries if particle orientation is random. $\oplus=$ over-exposure and $\ominus=$ under-exposure in XPL. 
All of these factors might explain why the empirical calibration method tends to overestimate the weights of coccoliths and why numerous different calibration curves have been published that exceed the maximum theoretically possible weight per pixel $(0.86 \mathrm{pg}$ assuming a pixel area of $0.0225 \mu \mathrm{m}^{2}$ and a maximum thickness of $1.41 \mu \mathrm{m}$ or $0.95 \mathrm{pg}$ assuming a maximum thickness of $1.56 \mu \mathrm{m}$ (for details see Bollmann (2013a, b)).

\subsection{Advantages and Limitations of the presented method}

The CPR-method has a number of advantages. The tuning of the illumination of the microscope to a grey value associated with a known retardation is quick and can be done any time to check the quality of tuning. Furthermore, it guarantees that results can be compared between different systems because calibration targets of known retardation can be used on any imaging system. The accuracy of the method is determined by theoretical considerations and there is no bias due to weighing errors, splitting errors, particle orientations and particle habitus, uneven particle distribution and aggregates, extinction pattern and over or underexposure. Last but not least, the area of a particle can be accurately calculated using a circular polarizer (CPL) as it eliminates the extinction pattern of XPL.

However, there are also some limitations: The weight of coccoliths with the $\mathrm{C}$-axis of their crystal units oriented parallel to the optical axis of the microscope can not be accurately estimated as they appear to be isotropic (dark in XPL; V-units according to Young and Bown (1997); e.g., discoasterids, coccoliths of the order Zygodiscales, Coccolithales and the family Syracosphaeraceae; Fig. 2i-p). Surprisingly the new method provides a good approximation of coccolith weights of C. leptoporus, Helicosphaera and Umbilicosphaera compared to the volumetric approach by Young and Ziveri (2000) if the thickness does not exceed the calibration range of $1.41 \mu \mathrm{m}$ thickness (large specimens). A possible explanation for the good agreement with volumetric estimates is that the V-units are not exactly oriented parallel to the optical axis of the microscope. This might be the case if coccoliths are not lying flat on the slide or if the orientation of the V-units within a coccolith is not exactly vertical. - Particles thinner than $0.04 \mu \mathrm{m}$ can not be measured as they can not be separated from the background ( $\sim$ grey value of 10 in this study; this limitation depends on the quality of the optics of the microscope and their alignment). - The most significant limitation of the method is the restriction to particles thinner than $\sim 1.41 \mu \mathrm{m}$. This mainly limits the application of the method to the analysis of flat lying single coccoliths. The stacked thickness of a side view of a single coccolith, for example an E. huxleyi coccolith with a length of 2.5 to $3.5 \mu \mathrm{m}$, clearly exceeds the limits of the applicability of a method based on weight estimates using the relationship between grey values derived from interference colours. In this respect, the accurate calculation of the weight of coccospheres using birefringence as reported by Beaufort et al. (2011) and Beaufort et al. (2008) appears to be challenging as the stacked thickness of coccoliths on a coccosphere can easily exceed $1.41 \mu \mathrm{m}$.

\subsection{Error considerations}

There are three main sources of error.

1. Accuracy of retardation calculation and weight estimates

2. Spatial resolution of the microscope

3. Dispersion colours

\subsubsection{Accuracy of retardation calculation and weight estimates}

The accuracy of the weight estimates depends on the accuracy/quality of the Michel-Lévy chart used for the estimates of particle thickness and the accuracy of the calibration of grey value for a known retardation. The recalculated MichelLévy chart by Sørensen (2013) is currently the most accurate calculation of interference colours and fits very well first order White. The accuracy of the grey value calculations using the recalculated Michel-Lévy chart by Sørensen (2013) was tested using polymers of known retardance values. First, the microscope was tuned to match the interference colour/grey value of a quarter wave platelet $(140 \mathrm{~nm} \pm 3 \mathrm{~nm}$ retardation; grey value $=194)$ and a grey value of $193 \pm 1 \mathrm{stdev}$ could be achieved. A half wave polymer retarder (retardance value of $275 \mathrm{~nm} \pm 3 \mathrm{~nm}$ corresponding to a thickness of $1.6 \mu \mathrm{m}$ ) showed an expected yellow interference colour and therefore, sits clearly outside of the calibration range of $0-249 \mathrm{~nm}$. The interference colour of a third polymer with a retardation of $165 \pm 3 \mathrm{~nm}$ revealed a grey value of $218 \pm 1$ stdev. The corresponding grey value based on the conversion of interference colours into grey values for a retardation of $165 \mathrm{~nm}$ is 217.

The smallest difference in thickness and weight (resolution/precision) that can be resolved is on average about $0.005 \mu \mathrm{m}$ and $0.013 \mathrm{pg}$ of calcite up to a grey value of 250 . From 251 to 253 one grey value corresponds to $0.16 \mathrm{pg}$ of calcite.

\subsubsection{Spatial resolution of the microscope}

The overall resolution/precision of the method also depends on the spatial resolution of the microscope. The theoretical spatial resolution of a microscope is determined by the numerical aperture of the objective (NA of 1.4 in this study) and the condenser (NA of 0.9 this study) and the wavelength of the light source (here $0.55 \mu \mathrm{m}$ ) and is calculated as follows:

ors $=\frac{1.22 \times \lambda}{\mathrm{NA}_{\mathrm{obj}}+\mathrm{NA}_{\mathrm{cond}}}$ 
where ors $=$ optical resolution; $\lambda=$ wavelength of the light used; $\mathrm{NA}_{\mathrm{obj}}=$ numerical aperture of the objective; $\mathrm{NA}_{\text {cond }}=$ numerical aperture of the condenser.

For the setup used in this study the theoretical resolution is $0.291 \mu \mathrm{m}$. However, a realistic practical resolution is closer to $0.5 \mu \mathrm{m}$ for the system used. Considering the optical resolution and the resolution of the thickness calculation, the resolution of the total weight estimation can be approximated as follows:

$w=a \times t m \times d$

Where $w=$ coccolith weight $(\mathrm{pg}) ; a=$ coccolith area $\left(\mu \mathrm{m}^{2}\right)$; $d=$ density (here $2.71 \mathrm{~g} \mathrm{~cm}^{-3}$ for calcite); $t_{\mathrm{m}}=$ mean thickness $(\mu \mathrm{m})$; the uncertainty in the mean thickness $\left(t_{\mathrm{m}}\right)$ corresponds to the thickness resolution $\left(t_{\mathrm{rs}} ; 0.005 \mu \mathrm{m}\right.$ in this study $)$ divided by $2\left(t_{\mathrm{m}} \pm t_{\mathrm{rs}} / 2\right)$.

$a=$ ael - caa

where ael $=$ area $\left(\mu \mathrm{m}^{2}\right)$ of an ellipse fit using length and width of the coccolith; caa = area of an ellipse fit using the length and width of the central area.

ael $=\pi \times\left(\frac{\left(\mathrm{cl} \pm \frac{\mathrm{ors}}{2}\right)}{2}\right) \times\left(\frac{\left(\mathrm{cw} \pm \frac{\mathrm{ors}}{2}\right)}{2}\right)$

where $\mathrm{cl}=$ coccolith length $(\mu \mathrm{m}) ; \mathrm{cw}=$ coccolith width $(\mu \mathrm{m})$; ors $=$ optical resolution $(0.291 \mu \mathrm{m}$ this study $)$;

caa $=\pi \times\left(\frac{\left(\mathrm{cal} \pm \frac{\mathrm{ors}}{2}\right)}{2}\right) \times\left(\frac{\left(\mathrm{caw} \pm \frac{\mathrm{ors}}{2}\right)}{2}\right)$

where cal $=$ length of central area $(\mu \mathrm{m})$; caw $=$ width of the central area $(\mu \mathrm{m})$.

Using this approach the weight is estimated assuming coccoliths are perfect ellipses. Further, special elements, for example, the bridge element spanning the central area of Gephyrocapsa spp. are not taken into account. The resolution of the weight estimate for G. oceanica given on Fig. 2r is about $\pm 2.16 \mathrm{pg}$ ( $\pm 12 \%$ of $18 \mathrm{pg}$ ). If an optical resolution of $0.5 \mu \mathrm{m}$ is assumed, the resolution of the weight estimate decreases to $\pm 3.6 \mathrm{pg}$ ( $\pm 20 \%$ of $18 \mathrm{pg})$.

\subsubsection{Dispersion colours}

Blue dispersion colours were often observed at the edge of coccoliths in XPL and CPL (Fig. 2) leading to increasing uncertainties in weight estimates. Accurate focussing and adjusting of the threshold for object detection reduces these artefacts but does not eliminate them. Different mounting media (different refractive index than Canada balsam) might reduce the problem as the phenomenon appears to be caused by differences in refractive index of the mounting medium and calcite resulting in a coloured Becke line. Opening the condenser aperture diaphragm to the maximum and the use of a 1.4NA oil condenser can also reduce this type of artefact (J. Delly, personal communication, 2013).

\subsection{Recommendations}

1. The new calculated Michel-Lévy colour chart of Sørensen (2013) for the calculation of grey values derived retardations should be used as it matches first order White better than former Michel-Lévy colour charts. Furthermore, the weight estimates should be restricted to a coccolith thickness of $1.27 \mu \mathrm{m}$ and the corresponding grey value of 250 because the resolution of the method declines significantly from $0.013 \mathrm{pg}$ to $0.16 \mathrm{pg}$ for grey values higher than 250 . This can be done in ImageJ by setting an upper threshold for the segmentation/detection of particles.

2. For the calibration of interference colour to grey value transformation, a polymer retarder mounted on a microscope slide and covered by a coverslip is recommended. Meadowlark optics (http://www.meadowlark. com) offers high precision polymer retarders, in particular Dichroic Polymer, accuracy $\pm \lambda / 300$; retardance @ 550 nm: $140 \mathrm{~nm}$. In order to test the quality/accuracy of the measurements, one or more retarder of the same polymer and of different retardance value (for example $165 \mathrm{~nm}$ ) can be used. Please note that different materials have different light transmission. Therefore, it is of utmost importance to use retarders for testing with the same transmittance/optical density as the retarders used for calibration. If coccoliths on membrane filters should be analysed, the polymer retarder has to be mounted on top of the membrane filter using the same type of glass slides and adhesives as used for the actual sample preparations. If membrane filters are used for the preparation, whether the membranes are birefringent should also be tested. For example, polycarbonate membranes are birefringent and affect the measurements as they can lower or increase the interference colour of calcite particles.

3. I further recommend the use of an illumination source with a colour temperature of $3200 \mathrm{~K}$. Modern microscopes have a predefined setting for microphotography at $3200 \mathrm{~K}$. This corresponds to $9 \mathrm{~V}$ using a $100 \mathrm{~W}$ halogen bulb. For details see: http://micro.magnet.fsu.edu/ primer/photomicrography/colortemperature.html).

Halogen bulbs can increase their luminosity with increasing age because the filament thins and thus the resistance decreases and the electric current increases. Therefore, it is recommend to check the illumination frequently by measuring the grey value of a calibration retarder.

4. An APS-CMOS camera instead of a CCD camera should be used since pixels of CCD cameras tend to "bleed" into neighbouring pixels at maximum exposure and produce a blooming effect that leads to wrong area and thickness calculations (for details 
see (http://spiff.rit.edu/classes/phys445/lectures/ccd2/ ccd2.html; http://en.wikipedia.org/wiki/Active_pixel_ sensor).

5. Since interference colours of particles thicker than $1.41 \mu \mathrm{m}$ can show the same grey value as thinner particles, it is recommended to use a colour camera and remove all particles that show colours higher than first order white before the image is transformed into a grey scale image. Furthermore, it should be noted that great care has to be taken when RGB colours are converted into grey values because there are different algorithms that can affect results (the same applies to black and white cameras, DSLR cameras). Most cameras encode JPEG and TIFF images with a GAMMA correction of 0.45 . However, that might differ among camera models. The colour chart of Sørensen (2013) is encoded with a GAMMA of 0.5. It is, therefore, recommended to either recalculate the colour chart (Sørensen, 2013) with the GAMMA correction of the camera used or correct the camera images with a GAMMA of 0.5 , when the RAW image format is accessible. For CANON DLSR cameras it is recommended to convert the RAW image format into Adobe DNG format and adjust the GAMMA to 0.5, for example in Photoshop and export the image as JPEG or TIFF. It is best to use the same imaging programme, for example ImageJ, to convert the Michel-Lévy chart and the microscope images into grey scale images to avoid calculation bias.

6. If the mean coccolith weight of a species from several samples is compared, a pilot study should be conducted first in order to estimate the expected standard deviation of the samples to be measured. The number of coccoliths per sample to be measured can then be calculated by:

$n=\frac{z^{2} \times \sigma^{2}}{\mathrm{er}^{2}}$

where $n=$ number of specimens; er $=$ Tolerable error \pm from the mean value; $\sigma$ expected standard deviation; $z=$ critical standard score, e.g., 1.96 for a $95 \%$ confidence interval.

For example, the mean weight of G. muellerae in GEOB3602 is $7.6 \mathrm{pg}$ and the $95 \%$ confidence interval for the mean value is $\pm 1.3 \mathrm{pg}$ (standard deviation is $\pm 2.7 \mathrm{pg}$ ). If the tolerable error for the mean value has to be smaller than $1.3 \mathrm{pg}$, for example, $1.0 \mathrm{pg}$ ( $\sim$ weight resolution of the new method), the number of measurements has to be increased from 16 to 28 measurements. The same approach can be used to determine the number of measurements required for any dimensional measurement (for details see http://stattrek.com/sample-size/ simple-random-sample.aspx).
7. The spraying method reported by Bollmann et al. (1999) and McIntyre et al. (1967) is the best approach to prepare sediment samples instead of the generic smear slide method as it provides well isolated coccoliths for a robust segmentation of coccoliths and outline detection. If filtered samples are required, modified inline filter gaskets as described by Bollmann et al. (2002) are recommended since they provide optimal particle distribution.

8. Vibrations can significantly reduce the spatial resolution of the microscope and thus increase the error on weight estimates. Therefore, the use of an antivibration table or table top is recommended.

9. If high spatial resolution is required, a 1.4NA oil condenser and/or a monochromatic light source, such as a sodium vapour lamp, are recommended (J. Delly, personal communication, 2013). However, the use of a monochromatic light requires the recalculation of the Michel-Lévy chart or establishing a calibration curve using several polymer retarders, for example, in $20 \mathrm{~nm}$ wide steps of retardance. Custom made polymer retarders are available from Meadowlark Optics, for example.

\subsection{Useful online resources:}

http://www.modernmicroscopy.com/

http://micro.magnet.fsu.edu

http://www.olympusmicro.com/index.html

http://www.microscopyu.com/

http://zeiss-campus.magnet.fsu.edu/

http://stattrek.com/sample-size/simple-random-sample.aspx

\section{Conclusions}

A new method to estimate the weight of single coccoliths is proposed. A circular polarizer and retardation measurements based on grey values derived from theoretical calculations allows for the first time accurate calculations of the weight of single coccoliths thinner than $1.37 \mu \mathrm{m}$. The proposed method overcomes most limitations of the weight transfer function as it is derived from theoretical considerations instead of empirical calibrations which tend to be more error prone. The simple calibration of the interference colour/grey level using a material with a known thickness/retardation and birefringence has several advantages. It is quick and can be done just before the actual batch of measurements. The accuracy of the calibration can be tested by measuring the grey values of material with known retardation different from the one used for calibration. It also provides the simple means to compare the results from different studies as standard retardation wave plates can be used to calibrate the interference colours on different systems. Furthermore, the use of 
the Benford plate overcomes the problem of extinction patterns in XPL and thus increases the accuracy of the weight estimates. This new imaging technique enables for the first time the imaging of complete coccoliths with maximum interference colour and therefore, it greatly simplifies the identification of coccolithophore species on a light microscope.

\section{Supplementary material related to this article is available online at http://www.biogeosciences.net/11/ 1899/2014/bg-11-1899-2014-supplement.pdf.}

Acknowledgements. Bjørn Eske Sørensen kindly provided his new colour chart in a resolution of $1 \mathrm{~nm}$ steps retardation and his Matlab scripts. This work would not have been possible without continuous support from Manuel Schneidereith, Customized Solutions, Olympus Soft Imaging Solutions GmbH. Comments from Michael Knappertsbusch, John Delly, Jens Olaf Herrle, Mara Yadira Cortés, Remo Cossu, Roman Kondrachov, Lana McInnis, Luc Beaufort, Jeremy Young, Christian Meier and Samantha Gibbs and colleagues helped to improve the ms.

Edited by: C. Klaas

\section{References}

Bach, L. T., Bauke, C., Meier, K. J. S., Riebesell, U., and Schulz, K. G.: Influence of changing carbonate chemistry on morphology and weight of coccoliths formed by Emiliania huxleyi, Biogeosciences, 9, 3449-3463, doi:10.5194/bg-9-3449-2012, 2012.

Bairbakhish, A. N., Bollmann, J., Sprengel, C., and Thierstein, H. R.: Disintegration of aggregates and coccospheres in sediment trap samples, Mar. Micropaleontol., 37, 219-223, 1999.

Bauke, C., Meier, K. J. S., Kinkel, H., and Baumann, K.-H.: Changes in coccolith calcification under stable atmospheric $\mathrm{CO}_{2}$, Biogeosciences Discussions, 10, 9415-9450, doi:10.5194/bgd10-9415-2013, 2013.

Beaufort, L. and Heussner, S.: Coccolithophorids on the continental slope of the Bay of Biscay - production, transport and contribution to mass fluxes, Deep-Sea Res. Pt. II, 46, 2147-2174, 1999.

Beaufort, L.: Weight estimates of coccoliths using the optical properties (birefringence) of calcite, Micropaleontol., 51, 289-298, 2005.

Beaufort, L., Probert, I., and Buchet, N.: Effects of acidification and primary production on coccolith weight: Implications for carbonate transfer from the surface to the deep ocean, Geochem. Geophys. Geosyst., 8, 1-18, doi:10.1029/2006GC001493, 2007.

Beaufort, L., Couapel, M., Buchet, N., Claustre, H., and Goyet, C.: Calcite production by coccolithophores in the south east Pacific Ocean, Biogeosciences, 5, 1101-1117, doi:10.5194/bg-5-11012008, 2008.

Beaufort, L., Probert, I., de Garidel-Thoron, T., Bendif, E. M., RuizPino, D., Metzl, N., Goyet, C., Buchet, N., Coupel, P., Grelaud, M., Rost, B., Rickaby, R. E. M., and de Vargas, C.: Sensitivity of coccolithophores to carbonate chemistry and ocean acidification, Nature, 476, 80-83, 2011.

Bloss, F. D.: An Introduction to the Methods of Optical Crystallography Holt, Philadelphia, Pa., 1961.

Bollmann, J.: Morphology and biogeography of Gephyrocapsa coccoliths in Holocene sediments, Mar. Micropaleontol., 29, 319350, 1997.

Bollmann, J., Brabec, B., Cortés, M. Y., and Geisen, M.: Determination of absolute coccolith abundances in deep-sea sediments by spiking with microbeads and spraying (SMS-method), Mar. Micropaleontol., 38, 29-38, 1999.

Bollmann, J., Quinn, P., Vela, M., Brabec, B., Brechner, S., Cortés, M. Y., Hilbrecht, H., Schmidt, D. N., Schiebel, R., and Thierstein, H. R.: Automated particle analysis: calcareous microfossils, in: Image Analysis, Sediments and Paleoenvironments, edited by: Francus, P., Springer, Berlin, New York, 229-252, 2004.

Bollmann, J. and Herrle, J. O.: Morphological variation of Emiliania huxleyi and sea surface salinity, Earth Planet. Sci. Lett., 255, 273-288 2007.

Bollmann, J., Klaas, C., and Brand, L. E.: Morphological and physiological characteristics of Gephyrocapsa oceanica var. typica Kamptner 1943 in culture experiments: evidence for genotypic variability, Protist, 161, 78-90, doi:10.1016/j.protis.2009.08.002, 2010.

Bollmann, J.: Interactive comment on "Technical Note: Weight approximation of single coccoliths inferred from retardation estimates using a light microscope equipped with a circular polarizer - (the CPR Method)" by J. Bollmann, Biogeosciences Discuss., 10, C6961-C6981, 2013a.

Bollmann, J.: Interactive comment on "Technical Note: Weight approximation of single coccoliths inferred from retardation estimates using a light microscope equipped with a circular polarizer - (the CPR Method)" by J. Bollmann, Biogeosciences Discuss., 10, C6989-C6994, 2013b.

Bordiga, M., Beaufort, L., Cobianchi, M., Lupi, C., Mancin, N., Luciani, V., Pelosi, N., and Sprovieri, M.: Calcareous plankton and geochemistry from the ODP site 1209B in the NW Pacific Ocean (Shatsky Rise): new data to interpret calcite dissolution and paleoproductivity changes of the last 450ka, Palaeogeogr. Palaeocl., 371, 93-108, 2012.

Broerse, A. T. C., Brummer, G. A., and Hinte, J. E. V.: Coccolithophore export production in response to monsoonal upwelling off Somalia (northwestern Indian Ocean), Deep-Sea Res. Pt. II, 47, 2179-2205, 2000.

Craig, D. B.: The Benford plate, The American mineralogist 46, 757-758, 1961.

Cubillos, J. C., Henderiks, J., Beaufort, L., Howard, W. R., and Hallegraeff, G. M.: Reconstructing calcification in ancient coccolithophores: Individual coccolith weight and morphology of Coccolithus pelagicus (sensu lato), Mar. Micropaleontol., 92-93, 29-39, 2012.

Delly, J. G.: The Michel-Lévy interference color chart - microscopy's magical color key, Modern microscopy Journal, http: //www.modernmicroscopy.com, 2003.

Doney, S. C., Fabry, V. J., Feely, R. A., and Kleypas, J. A.: Ocean Acidification: The other $\mathrm{CO}_{2}$ problem, Annu. Rev. Mar. Sci., 1, 169-192, 2009. 
Engel, A., Zondervan, I., Beaufort, L., Benthien, A., Delille, B., Villefranche, D., Harlay, J., Heemann, C., Hoffmann, L., Nejstgaard, J., Rochelle-newall, E., Schneider, U., and Terbrueggen, A.: Testing the direct effect of $\mathrm{CO}_{2}$ concentration on a bloom of the coccolithophorid Emiliania huxleyi in mesocosm experiments, Limnol. Oceanogr., 50, 493-507, 2005.

Frohlich, W.: Bifringent objects visualized by circular polarization microccopy, Stain technology, 61, 139-143, 1986.

Grelaud, M., Schimmelmann, A., and Beaufort, L.: Coccolithophore response to climate and surface hydrography in Santa Barbara Basin, California, AD 1917-2004, Biogeosciences, 6, 2025-2039, doi:10.5194/bg-6-2025-2009, 2009.

Guay, C. K. H. and Bishop, J. K. B.: A rapid birefringence method for measuring suspended $\mathrm{CaCO}_{3}$ concentrations in seawater, Deep-Sea Res. I, 49, 197-210, 2002.

Higgins, M.: Imaging birefringent minerals without extinction using circularly polarized light, The Canadian Mineral., 48, 231-235, 2010.

Horigome, M. T., Ziveri, P., Grelaud, M., Baumann, K.-H., Marino, G., and Mortyn, P. G.: Environmental controls on the Emiliania huxleyi calcite mass, Biogeosciences Discuss., 10, 9285-9313, doi:10.5194/bgd-10-9285-2013, 2013.
Knappertsbusch, M., Cortes, M. Y., and Thierstein, H. R.: Morphologic variability of the coccolithophorid Calcidiscus leptoporus in the plankton, surface sediments and from the Early Pleistocene, Mar. Micropaleontol., 30, 293-317, 1997.

McIntyre, A., Bé, A. W. H., and Preikstas, R.: Coccoliths and the Pliocene-Pleistocene boundary, Prog. Oceanogr., 4, 3-25, 1967.

Parente, A., Cachão, M., Baumann, K.-H., Abreu, L. D., and Ferreira, J.: Morphometry of Coccolithus pelagicus s.l. (Coccolithophore, Haptophyta) from offshore Portugal, during the last $200 \mathrm{kyr}, 50,107-120,2004$.

Quinn, P. S., Cortes, M. Y., and Bollmann, J.: Morphological variation in the deep ocean-dwelling coccolithophore Florisphaera profunda (Haptophyta), Eur. J. Phycol., 40, 123-133, 2005.

Raith, M. M., Raase, P., and Reinhardt, J.: Guide to Thin Section Microscopy, 2nd Edn., 2012.

Sørensen, B. E.: A revised Michel-Lévy interference colour chart based on first-principles calculations, Eur. J. Mineral., 25, 5-10, 2013.

Young, J. R. and Bown, P. R.: Higher classification of calcareous nannofossils, J. Nannoplankton Res., 19, 15-20, 1997.

Young, J. R., and Ziveri, P.: Calculation of coccolith volume and its use in calibration of carbonate flux estimates, Deep-Sea Res. Pt. II, 47, 1679-1700, 2000.

Zhang, P., Tan, Y., Liu, W., and Chen, W.: Methods for optical phase retardation measurement: a review, Sci. China Technol. Sci., 56, 1155-1164, doi:10.1007/s11431-013-5207-4, 2013. 